\title{
Foreword
}

\section{Elbowing Our Way Beyond Tommy John}

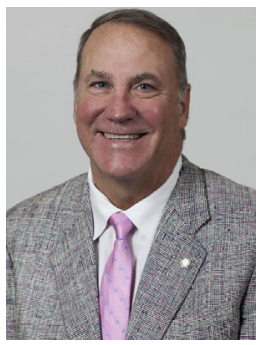

Mark D. Miller, MD

Consulting Editor

Dr Frank Jobe rocked the sports medicine world when he performed the first ulnar collateral ligament (UCL) reconstruction in 1974. Almost a half century later, we can reflect on the contributions of other sports medicine elbow pioneers, including $\mathrm{Dr}$ James Andrews, Dr Neal ElAttrache, and many of the authors of this issue of Clinics in Sports Medicine, including the Editor, Dr Jeff Dugas. This issue nicely summarizes the current state-of-the-art of sports-related elbow injuries to include not only the UCL but also other ligaments, tendons, fractures, dislocations, and nerve injuries involving this important joint. My sincere appreciation to Dr Jeff Dugas, who did a stellar job in putting together this issue. This is an excellent issue of Clinics in Sports Medicine that I encourage all to read and study.

\author{
Mark D. Miller, MD \\ Division of Sports Medicine \\ Department of Orthopaedic Surgery \\ University of Virginia \\ James Madison University \\ 400 Ray C. Hunt Drive, Suite 330 \\ Charlottesville, VA 22908-0159, USA \\ E-mail address: \\ mdm3p@virginia.edu
}

